\title{
Manejo de plantas medicinales en el nororiente amazónico peruano
}

\section{Management of medicinal plants in the northeastern Peruvian Amazon}

\author{
María del Pilar Rodríguez Quezada
}

Universidad Nacional Toribio Rodríguez de Mendoza-Amazonas

Facultad de Enfermería, Ciudad Universitaria, Higos Urco s/n

\section{RESUMEN}

Estudio descriptivo, exploratorio, de diseño transversal, cuyo objetivo fue estudiar el manejo de las plantas medicinales en 47 agentes comunitarios de medicina tradicional del nororiente amazónico peruano. Ellos fueron entrevistados para identificar las plantas medicinales que crecen silvestres o cultivadas en las 21 comunidades visitadas y las plantas que ellos usan para tratar enfermedades, describiendo la forma de recolección y almacenaje de las plantas, así como el uso, preparación y parte usada (cantidad) de la planta medicinal. Se identificaron 238 plantas medicinales usadas por los agentes comunitarios tradicionales, de los cuales 155 son usadas individualmente para tratar o prevenir enfermedades, las demás en forma complementaria con otras plantas; 193 son usadas cotidianamente por los pobladores de las regiones de Amazonas, Loreto y San Martín; 100 especies fueron cultivadas e identificadas taxonómicamente en el jardín botánico de plantas medicinales de la Universidad Nacional Toribio Rodríguez de Mendoza de Amazonas. Las plantas medicinales son usadas en infusiones $71.6 \%$, cocimientos $38.7 \%$, zumos $8.4 \%$, frotaciones $6.5 \%$, emplastos y los baños $5.8 \%$, cataplasmas $5.2 \%$. Tienen un gran potencial agroindustrial: medicinal, culinario, plaguicida, etnoveterinaria, cosmético entre otros.

Descriptores: manejo, recolección, almacenamiento, uso de plantas medicinales amazónicas.

\section{ABSTRACT}

Descriptive, exploratory study, of cross-sectional design, whose objective was to study the management of medicinal plants at 47 community agents of traditional medicine of the northeastern Peruvian Amazon. They were interviewed to identify medicinal plants that grow wild or cultivated in the 21 communities visited and the plants that they use to treat diseases, describing the form of collection and storage of plants, and the use, preparation and part used (amount) of the plants. It identified 238 medicinal plants used by traditional community agents, of which 155 are used individually to treat or prevent disease, the other in a complementary way with other plants; 193 are also used daily by people from the regions of Amazonas, Loreto and San Martin; 100 species were cultured and identified taxonomically in the botanical garden of medicinal plants of the National University Toribio Rodriguez de Mendoza of Amazonas. Medicinal plants are used in infusions $71,6 \%$, decoctions $38,7 \%$, juices $8.4 \%$, rubs $6,5 \%$, poultices and baths $5.8 \%$, poultices $5.2 \%$. They have a great potential for agribusiness: medicinal, culinary, pesticidal, ethno-veterinary, cosmetic, among others. 
ECIPERÚ

\section{INTRODUCCIÓN}

La Amazonía peruana tiene una extensión aproximada de 74 millones de ht, es decir el $61 \%$ del país, tiene recursos minero-energéticos, gran diversidad biológica, diferentes ecosistemas, valiosas prácticas y conocimientos depositados en los pueblos amazónicos. Sin embargo estos recursos están en proceso de disminución, por lo que economía amazónica deberá sustentarse en el aprovechamiento y manejo de los recursos renovables de su diversidad biológica [1].

Existen algunas experiencias en otros países como Chile, donde existe un proyecto de recuperación y difusión de la medicina tradicional mediante la recolección y manejo de plantas medicinales existentes en la localidad de Codpa para posteriormente incentivar al cultivo de especies para un manejo protegido [2]

Otra experiencia en Costa Rica llevada a cabo por estudiantes, profesores y padres de familia quienes conjuntamente han trabajado en la promoción del uso inteligente de las plantas medicinales y el rescate de las costumbres practicadas por los abuelos en el uso de plantas medicinales, así como la investigación, reproducción y manejo de las mismas [3].

Las Regiones Amazonas, Loreto y San Martín, al estar ubicadas en el sector nororiental del territorio peruano, próxima a la línea ecuatorial y en una zona de transición entre los Andes y el llano amazónico, presenta diversas gradientes de pisos ecológicos que dan origen a un mosaico variado de ecosistemas y zonas de vida que albergan una gran diversidad de especies de flora y fauna consideradas endémicas y de alto valor y prioridad para la conservación a nivel regional, nacional y global.

Las especies de plantas, aprovechadas como alimentos, remedios o materias primas, varían de una zona a otra, de un pueblo a otro, inclusive a las mismas especies. Únicamente comparando y juntando los conocimientos de varios pueblos acerca de una especie nos dará una visión más completa de sus características y su potencial de uso.

Los pueblos awajún y wampís distinguen más de 400 especies de plantas nativas para fines utilitarios de medicinas, alimentación, construcción, fibras, tintes, colorantes y aceites [4]. Sin embargo siembran varias especies en una misma chacra, principalmente cultivos de uso alimenticio y medicinal.

Estos antecedentes motivaron hacer un análisis metódico del manejo (forma de recolección, almacenamiento, preparación y usos) de las plantas medicinales en el nororiente del Perú, como medicina alternativa para tratar diversas enfermedades, colectar y sembras algunas especies en un jardín botánico, para la recuperación de la biodiversidad de plantas medicinales ancestrales y como fuente de estudios posteriores.

\section{METODOLOGÍA}

Se trabajó con 47 agentes comunitarios del nororiente amazónico peruano (Regiones de Amazonas, San Martín y Loreto). Para ubicarlos se visitaron las provincias del nororiente peruano, reconocidas por el uso de plantas medicinales: Bagua, Bongará, Chachapoyas, Rodríguez de Mendoza, Luya, Utcubamba (Región Amazonas), Lamas, Tarapoto, Moyobamba (Región San Martín) e Iquitos (Región Loreto).

Los agentes comunitarios fueron entrevistados acerca del manejo de las plantas medicinales: recolección, almacenamiento, preparación y uso de las plantas medicinales. Aplicándoseles el Formulario 01: Fuentes de productos vegetales como medicina alternativa, para identificar las plantas medicinales silvestres, cultivadas en la zona; el Formulario 02: Uso de las plantas, que recogió información sobre la forma de preparación, parte usada de la planta (cantidad) y frecuencia de uso; el Formulario 3: Identificación de los Agentes Comunales: tipo de agente comunal, su edad, residencia actual, referencia, grado de instrucción y ocupación actual.

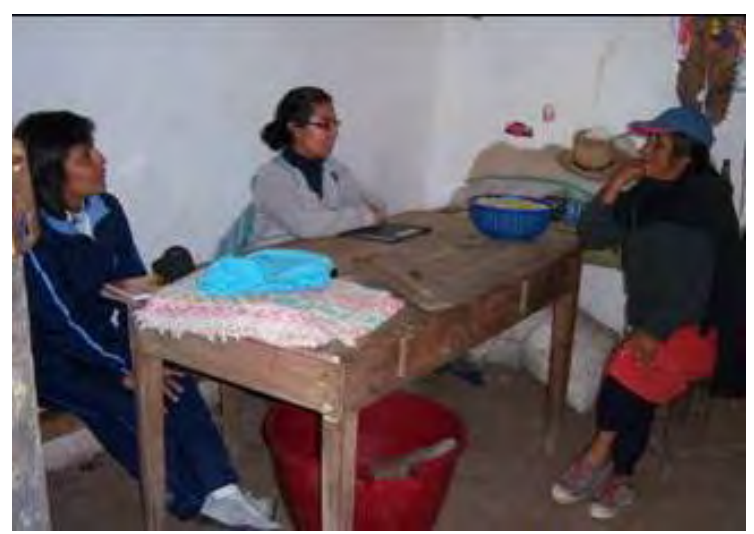

Figura 1: Entrevista a una agente de la medicina tradicional (partera) en la localidad de Soloco, Provincia de Chachapoyas, Amazonas.

Se coordinó con ellos para la identificación y adquisición de algunas plantas medicinales para su cultivo en un jardín botánico ubicado en la Universidad Nacional Toribio Rodríguez de Mendoza de Amazonas y el posterior análisis del potencial agroindustrial de las mismas. 


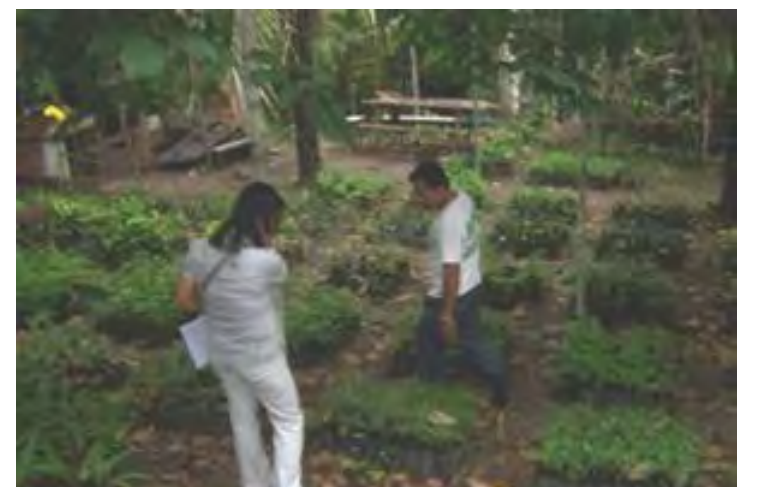

Figura 2: identificación y adquisición de algunas plantas medicinales en Quistococha, Iquitos.

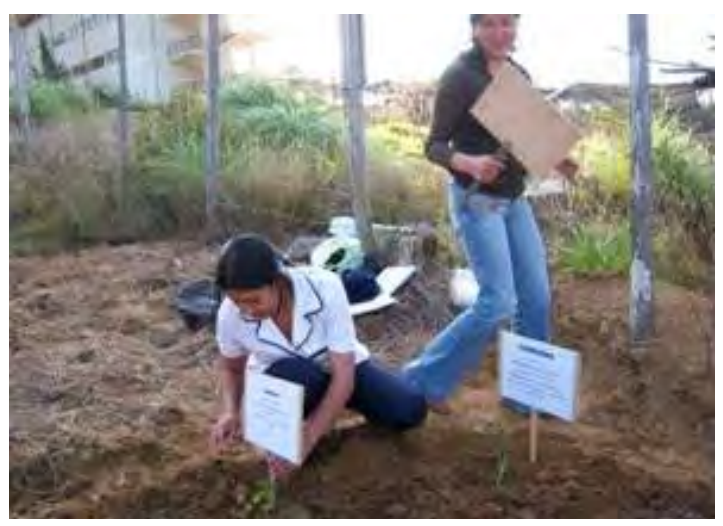

Figura 3: cultivo de plantas medicinales recolectadas, en un jardín botánico ubicado en la Universidad Nacional Toribio Rodríguez de Mendoza de Amazonas.

\section{RESULTADOS Y DISCUSIÓN}

El nororiente amazónico peruano proporciona una gama de flora con valor medicinal altamente significativo, usada por los agentes comunitarios de medicina tradicional entrevistados, 31 eran curanderos, 10 parteras, 1 huesero y 5 naturistas. El $29,8 \%$ de ellos refieren que el lugar de recolección de las mejores especies de plantas medicinales, mayormente debe ser de tierra negra y seca; pero el $19,1 \%$ refiere que debe ser tierra negra y húmeda (Ver Gráfico1).

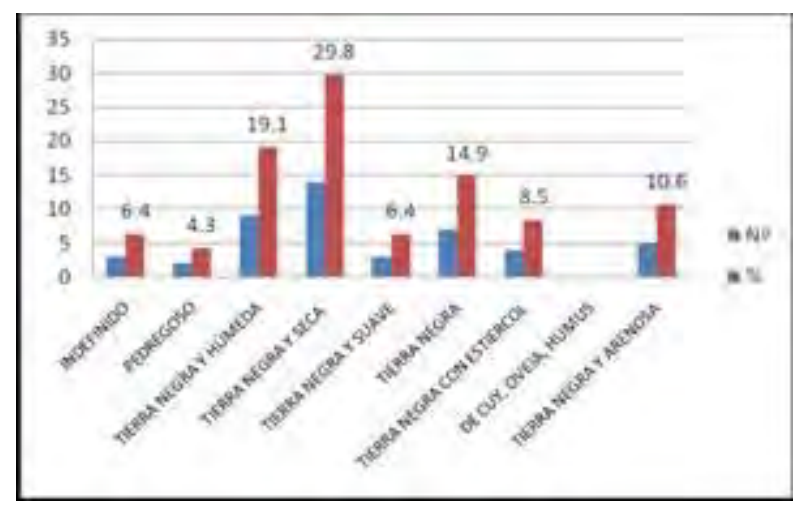

Gráfico 1: Características del lugar de recolección de las mejores especies de plantas medicinales del nororiente amazónico peruano.

El hábitat de una especie medicinal debe ser registrado para poder establecer su ecología y su distribución, así como también para proyectar su posible manejo y/o domesticación y determinar que plantas son las más utilizadas para una enfermedad y evaluar las cantidades extraídas y/o usadas, además, así se facilitan las estimaciones del valor económico de las plantas medicinales extraídas para consumo y/o venta [5].

Usualmente los suelos de la amazonia peruana no son aptos para la agricultura [6], el identificar las características del lugar de recolección de las plantas medicinales, permitirá recrear un hábitat con condiciones similares donde se cultiven estas especies medicinales incrementando la capacidad económica de los pobladores de la región.

El manejo racional de las poblaciones naturales de plantas nativas puede permitir el uso de tales suelos e integrarse como parte importante de un programa regional de ecodesarrollo [6].

Muchas de las plantas en el nororiente amazónico peruano crecen en forma silvestre sin el cuidado en su cultivo, cosecha y almacenamiento. Los agentes de la medicina tradicional suelen recolectar las plantas y usarlas inmediatamente. Por eso el 51,1\% refiere que no las almacenan; pero un $12,8 \%$ lo hace en bolsas, bajo sombra en zonas ventiladas y un porcentaje menor en depósitos improvisados como tinas, cerca de la cocina a veces en lugares oscuros o en lugares muy iluminados, no existen estándares en el tiempo de almacenamiento, el $26,8 \%$ lo hace hasta 2 semanas, el $12,2 \%$ hasta 6 meses y el $4,9 \%$ por varios años (Ver Gráficos 2 y 3).

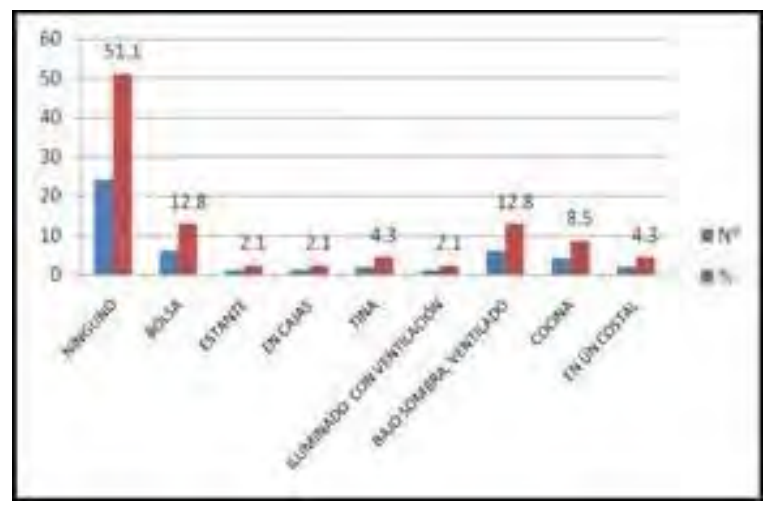

Gráfico 2: Almacenamiento de las plantas medicinales del nororiente amazónico peruano. 


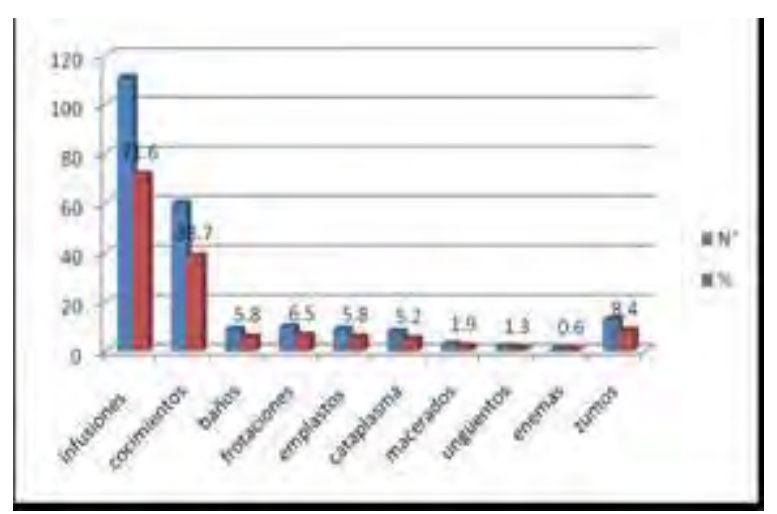

Gráfico 3: Tiempo de almacenamiento de las plantas medicinales del nororiente amazónico.

Los preparados de plantas medicinales que mayormente usan los agentes de la medicina tradicional del nororiente amazónico peruano son las infusiones $71,6 \%$ y cocimiento $38,7 \%$ (Ver Gráfico $4)$.

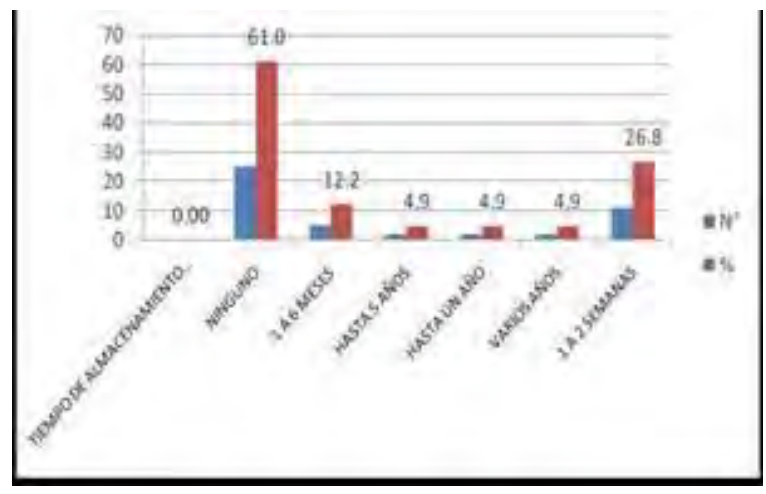

Gráfico 4: Preparados de plantas medicinales usados en el nororiente amazónico peruano.

Saber cómo utilizar las diferentes plantas es importante a la hora de elegir. Para la combinación de hierbas existen determinadas reglas. Las mezclas suelen incluir en su fórmula una hierba base, específica para la dolencia que se vaya a tratar, y otras que contribuyen a lograr los efectos buscados $y$, en algunos casos, permiten corregir el sabor amargo 0 desagradable de ciertas plantas medicinales. El uso de una sola planta medicinal, sin que se haya mezclado con otros elementos y con una dosificación precisa, para una enfermedad bien definida indica qué efectos son más probables [5]. La información proporcionada por los agentes comunitarios acerca las plantas medicinales que ellos usan se presentan en la Tabla 1.

Tabla1: Plantas medicinales del nororiente y amazónico peruano.

ECIPERÚ

\begin{tabular}{|c|c|c|c|}
\hline $\begin{array}{c}\text { PLANTA } \\
\text { MEDICINAL }\end{array}$ & \begin{tabular}{|c|} 
NOMBRE \\
CIENTİFICO \\
DE PLANTA \\
MEDICINAL \\
\end{tabular} & $\begin{array}{c}\text { ENFERMEDAD } \\
\text { QUE } \\
\text { PREVIENE O } \\
\text { CURA } \\
\end{array}$ & PREPARADO \\
\hline acelga & $\begin{array}{l}\text { Beta vulgaris } \\
\text { var. cicla } L \text {. }\end{array}$ & $\begin{array}{l}\text { infección del } \\
\text { estómago, } \\
\text { retención } \\
\text { urinaria }\end{array}$ & $\begin{array}{l}\text { Machacar } 5 \text { raíces, colocar } \\
\text { en agua hervida, (infusión) } \\
\text { tomar en ayunas. }\end{array}$ \\
\hline \multirow{3}{*}{ achicoria } & \multirow{3}{*}{$\begin{array}{l}\text { Picrosia } \\
\text { longifolia D. } \\
\text { Don. }\end{array}$} & cefalea & $\begin{array}{l}\text { Machacar } 6 \text { hojas y tallos, } \\
\text { tomar el zumo. }\end{array}$ \\
\hline & & Fiebre & $\begin{array}{l}\text { Machacar } 5 \text { gr de semillas, } \\
\text { colar y tomar el jugo. }\end{array}$ \\
\hline & & hígado & $\begin{array}{l}\text { Cocimiento de una planta } \\
\text { entera. }\end{array}$ \\
\hline achote & Bixa orellana & $\begin{array}{l}\text { prostatitis, } \\
\text { inflamación del } \\
\text { riñón }\end{array}$ & $\begin{array}{l}\text { Infusión en un litro de agua } \\
\text { de } 20 \text { gr de hojas. }\end{array}$ \\
\hline \multirow[b]{2}{*}{ ajenjo } & \multirow{2}{*}{$\begin{array}{l}\text { Artemisia } \\
\text { absinthium } \\
\text { L. }\end{array}$} & gripe & $\begin{array}{l}\text { Infusión en un litro de agua } \\
\text { de } 15 \text { gr de hojas. }\end{array}$ \\
\hline & & $\begin{array}{l}\text { menstruación } \\
\text { irregular }\end{array}$ & $\begin{array}{l}\text { Cocer } 20 \text { hojas y agregar } \\
\text { un vaso de chuchuwasi, y } \\
\text { una copa de algarrobina. }\end{array}$ \\
\hline \multirow{4}{*}{ albahaca } & \multirow{4}{*}{$\begin{array}{l}\text { Ocimun } \\
\text { basilicum }\end{array}$} & cólicos & Infusión de 4 ramas. \\
\hline & & $\begin{array}{l}\text { Infección del } \\
\text { trato urinario }\end{array}$ & $\begin{array}{l}\text { Infusión de } 3 \text { ramas, tomar } \\
3 / 4 \text { de taza. }\end{array}$ \\
\hline & & $\begin{array}{l}\text { Favorece } \\
\text { dilatación del } \\
\text { cuello uterino en } \\
\text { el parto }\end{array}$ & $\begin{array}{l}\text { Machacar las hojas y tallos } \\
\text { de una planta, exprimir y } \\
\text { tomar el zumo. }\end{array}$ \\
\hline & & $\begin{array}{l}\text { Calentamiento } \\
\text { durante el parto }\end{array}$ & Infusión de una rama \\
\hline \multirow[b]{2}{*}{ alfalfa } & \multirow[b]{2}{*}{$\begin{array}{l}\text { Medicago } \\
\text { sativa }\end{array}$} & $\begin{array}{l}\text { Buen } \\
\text { nacimiento }\end{array}$ & $\begin{array}{l}\text { Infusión de } 20 \text { hojas en un } \\
\text { litro de agua. }\end{array}$ \\
\hline & & anemia & $\begin{array}{l}\text { Jugo de los tallos y hojas } \\
\text { de una rama, tomar } \\
\text { durante } 9 \text { mañanas } \\
\text { consecutivas. }\end{array}$ \\
\hline algodón & $\begin{array}{l}\text { Gossypium } \\
\text { barbadense } \\
\text { L. }\end{array}$ & $\begin{array}{l}\text { problemas del } \\
\text { hígado }\end{array}$ & $\begin{array}{l}\text { Tomar una copita de salvia } \\
\text { del capullo en ayunas por } \\
9 \text { días, reposar } 4 \text { días } \\
\text { luego tomar por } 9 \text { días, ir } \\
\text { disminuyendo la dosis en } \\
\text { un mes. }\end{array}$ \\
\hline \multirow[b]{2}{*}{ aliso } & \multirow[b]{2}{*}{$\begin{array}{l}\text { Alnus } \\
\text { acuminata }\end{array}$} & dolor de cabeza & $\begin{array}{l}\text { Colocar } 2 \text { a } 4 \text { hojas sobre } \\
\text { la frente y cubrir con una } \\
\text { pañoleta. }\end{array}$ \\
\hline & & resfrió & $\begin{array}{l}\text { Mezclar las hojas con orina } \\
\text { o agua ardiente, colocar en } \\
\text { todo el cuerpo como } \\
\text { emplasto. }\end{array}$ \\
\hline anis & \begin{tabular}{|l|} 
Tagetes \\
filifolia Lag.
\end{tabular} & cólicos & Infusión de una rama. \\
\hline apio & \multirow{3}{*}{$\begin{array}{l}\text { Apium } \\
\text { graveolens } \\
\text { L. }\end{array}$} & $\begin{array}{l}\text { dispepsia, } \\
\text { diarrea, cólico }\end{array}$ & Infusión de una rama.. \\
\hline \multirow{2}{*}{ apio } & & hipotermia & Infusión de una rama.. \\
\hline & & diarrea & Infusión de una rama.. \\
\hline azucena & $\begin{array}{l}\text { Lilium } \\
\text { candidum L. }\end{array}$ & $\begin{array}{l}\text { depresión, } \\
\text { autoestima baja }\end{array}$ & $\begin{array}{l}\text { Baño, o tomar el zumo de } \\
5 \text { flores. }\end{array}$ \\
\hline boldo & & $\begin{array}{l}\text { problemas } \\
\text { respiratorios }\end{array}$ & $\begin{array}{l}\text { Infusión } 20 \text { gr de hojas en } \\
\text { un litro de agua.. }\end{array}$ \\
\hline borraja & $\begin{array}{l}\text { Borago } \\
\text { officinalis } L .\end{array}$ & tos & $\begin{array}{l}\text { Cocimiento de una planta } \\
\text { entera, tomar como agua } \\
\text { de tiempo. }\end{array}$ \\
\hline $\begin{array}{l}\text { botoncillo } \\
\text { neçro }\end{array}$ & & fiebre & $\begin{array}{l}\text { Cocer } 3 \text { ramas con sal, } \\
\text { licor y jugo de limón, tomar } \\
\text { una copa. }\end{array}$ \\
\hline cad lo & $\begin{array}{l}\text { Bidens } \\
\text { andicola } \\
\text { H.B.K. }\end{array}$ & $\begin{array}{l}\text { Infección del } \\
\text { trato urinario }\end{array}$ & $\begin{array}{l}\text { Cocer las hojas junto con } \\
\text { cascara de piña y barba } \\
\text { de choclo, tomar } 3 \\
\text { veces/día. }\end{array}$ \\
\hline $\begin{array}{c}\text { callo } \\
\text { manzanilla }\end{array}$ & $\begin{array}{l}\text { Tanacetum } \\
\text { parthenium }\end{array}$ & gripe & $\begin{array}{l}\text { Agregar a las hojas de una } \\
\text { rama timolina, sobar la } \\
\text { nariz del paciente. Infusión } \\
\text { de una rama. }\end{array}$ \\
\hline $\begin{array}{l}\text { campanilla } \\
\text { roja y blanca }\end{array}$ & $\begin{array}{l}\text { Ipoemoea } \\
\text { purpurea (L.) } \\
\text { Roth. }\end{array}$ & $\begin{array}{l}\text { Recaída } \\
\text { (problemas en } \\
\text { el puerperio), } \\
\text { dolor }\end{array}$ & $\begin{array}{l}\text { Lavar las heridas con el } \\
\text { cocimiento de un manojo } \\
\text { de hojas y flores, debe ser } \\
\text { tibio pasar por las zonas } \\
\text { de dolor. }\end{array}$ \\
\hline \multirow[t]{2}{*}{ canchalagua } & \multirow[t]{2}{*}{$\begin{array}{l}\text { Schkuhria } \\
\text { pinnata }\end{array}$} & $\begin{array}{l}\text { menstruación } \\
\text { irregular }\end{array}$ & $\begin{array}{l}\text { Infusión de un puñado de } \\
\text { flores y hojas, tomar } 1 \text { taza } \\
\text { por la mañana y noche } \\
\text { desde } 5 \text { días antes de la } \\
\text { menstruación. }\end{array}$ \\
\hline & & $\begin{array}{l}\text { problemas } \\
\text { circulación }\end{array}$ & $\begin{array}{l}\text { Cocimiento de } 20 \text { gr de } \\
\text { flores en un litro de agua.. }\end{array}$ \\
\hline
\end{tabular}


Volumen 8, número 2, agosto 2011

\begin{tabular}{|c|c|c|c|}
\hline caña & $\begin{array}{l}\text { Saccharum } \\
\text { officinarum } L .\end{array}$ & $\begin{array}{l}\text { Infección del } \\
\text { tracto } \\
\text { urinario }\end{array}$ & $\begin{array}{l}\text { Machacar } 5 \text { raíces, } \\
\text { tomar el, zumo. }\end{array}$ \\
\hline $\begin{array}{l}\text { cardo } \\
\text { santo }\end{array}$ & $\begin{array}{l}\text { Argemone } \\
\text { subfusiformis }\end{array}$ & $\begin{array}{l}\text { inflamación, } \\
\text { infección } \\
\text { dérmica, } \\
\text { diurético }\end{array}$ & $\begin{array}{l}\text { Infusión de } 10 \text { ramas } \\
\text { pequeñas en un litro de } \\
\text { agua. }\end{array}$ \\
\hline \multirow[b]{2}{*}{ carqueja } & \multirow[b]{2}{*}{ Baccharis crispa } & hepatitis & $\begin{array}{l}\text { Infusión de una planta } \\
\text { entera en un litro de } \\
\text { agua, tomar dos veces } \\
\text { al día. }\end{array}$ \\
\hline & & $\begin{array}{l}\text { problemas } \\
\text { del hígado }\end{array}$ & $\begin{array}{l}\text { Cocimiento de las hojas } \\
\text { de una planta entera, } \\
\text { chancar la raíz y tomar } \\
\text { en infusión } 3 \text { veces al } \\
\text { día por } 3 \text { a } 4 \text { días, } \\
\text { tomar luego mañana y } \\
\text { noche. }\end{array}$ \\
\hline cebolla & Allium cepa $L$. & tos & $\begin{array}{l}\text { Cocimiento de un fruto, } \\
\text { tomar con tamarindo. }\end{array}$ \\
\hline \multirow[t]{2}{*}{ cedrón } & \multirow[t]{2}{*}{ Aloysia triphylla } & $\begin{array}{l}\text { resfrió, } \\
\text { espasmo, } \\
\text { calienta } \\
\text { huesos }\end{array}$ & $\begin{array}{l}\text { Infusión de un puñado } \\
\text { de hojas. }\end{array}$ \\
\hline & & \begin{tabular}{ll|}
$\begin{array}{l}\text { dolor } \\
\text { cabeza }\end{array}$ & de \\
\end{tabular} & Infusión de las hojas. \\
\hline cerrajilla & $\begin{array}{l}\text { Sonchus oleraceus } \\
\text { L. }\end{array}$ & cólicos & Infusión de las hojas. \\
\hline ciruelo & $\begin{array}{l}\text { Prunus domestica } \\
\text { L. }\end{array}$ & $\begin{array}{l}\text { Atonía } \\
\text { uterina en el } \\
\text { trabajo de } \\
\text { parto }\end{array}$ & $\begin{array}{l}\text { Infusión de las hojas } \\
\text { dos veces }\end{array}$ \\
\hline $\begin{array}{l}\text { clavel } \\
\text { blanco }\end{array}$ & $\begin{array}{l}\text { Dianthus } \\
\text { caryophyllus }\end{array}$ & $\begin{array}{l}\text { Depresión, } \\
\text { autoestima } \\
\text { baja }\end{array}$ & Baño, zumo de 5 flores. \\
\hline \multirow{3}{*}{ coca } & \multirow{3}{*}{ Erythroxylum coca } & neumonía & Infusión de 5 hojas. \\
\hline & & parto & $\begin{array}{l}\text { Mezclar } 5 \text { hojas con } \\
\text { agua ardiente, manteca } \\
\text { de chancho (emplasto). }\end{array}$ \\
\hline & & parto & $\begin{array}{l}\text { Infusión de una porción } \\
\text { de hojas. }\end{array}$ \\
\hline col & Brassica oleracea & úlcera & $\begin{array}{l}\text { Licuar } 10 \text { hojas de col } \\
\text { en agua hervida (jugo), } \\
\text { tomar } 1 / \text { día. }\end{array}$ \\
\hline \multirow{3}{*}{$\begin{array}{l}\text { cola de } \\
\text { caballo }\end{array}$} & \multirow{3}{*}{$\begin{array}{l}\text { Equisetum } \\
\text { giganteum }\end{array}$} & $\begin{array}{l}\text { problemas } \\
\text { renales, } \\
\text { prostatitis, }\end{array}$ & $\begin{array}{l}\text { Infusión, cocimiento de } \\
6 \text { tallos. }\end{array}$ \\
\hline & & $\begin{array}{l}\text { retención } \\
\text { urinaria, } \\
\text { inflamación, } \\
\text { infecciones }\end{array}$ & $\begin{array}{l}\text { Cocimiento de un } \\
\text { manojo de tallos, tomar } \\
\text { como agua de tiempo. }\end{array}$ \\
\hline & & \begin{tabular}{ll|} 
dolor de \\
parto
\end{tabular} & $\begin{array}{l}\text { Cocimiento de la planta } \\
\text { entera. }\end{array}$ \\
\hline \multirow[b]{2}{*}{ congona } & \multirow[b]{2}{*}{$\begin{array}{l}\text { Peperomia } \\
\text { chachapoyasensis }\end{array}$} & luxaciones & Frotación con 6 ramas. \\
\hline & & mareos & $\begin{array}{l}\text { Sobar hojas de una } \\
\text { rama y hacer oler al } \\
\text { paciente. }\end{array}$ \\
\hline copaiba & $\begin{array}{l}\text { Copaifera paupera } \\
\text { (Herzog) Dwyer }\end{array}$ & inflamación & $\begin{array}{l}\text { Remojar un trozo de } \\
\text { corteza en agua, tomar } \\
\text { por } 8 \text { días (macerado). }\end{array}$ \\
\hline \multirow{2}{*}{ culantrillo } & \multirow{2}{*}{$\begin{array}{l}\text { Adiantum } \\
\text { digitatum Hooker }\end{array}$} & $\begin{array}{l}\text { limpiar } \\
\text { coágulos }\end{array}$ & Infusión de 2 ramas. \\
\hline & & $\begin{array}{l}\text { menstruació } \\
\mathrm{n} \text { irregular }\end{array}$ & $\begin{array}{l}\text { Infusión de las hojas y } \\
\text { tallos de planta entera. }\end{array}$ \\
\hline \multirow{2}{*}{$\begin{array}{c}\text { Chancapie- } \\
\text { dra }\end{array}$} & \multirow{2}{*}{$\begin{array}{l}\text { Phyllanthus niruri } \\
\text { L. }\end{array}$} & $\begin{array}{l}\text { dolor } \\
\text { ovarios }\end{array}$ & Cocimiento de 10 hojas. \\
\hline & & $\begin{array}{l}\text { cálculos } \\
\text { renales }\end{array}$ & $\begin{array}{l}\text { Infusión de en un litro } \\
\text { de agua. }\end{array}$ \\
\hline \multirow[t]{2}{*}{$\begin{array}{l}\text { chilca, } \\
\text { chishca }\end{array}$} & \multirow[t]{2}{*}{ Baccharis chilca } & luxaciones & $\begin{array}{l}\text { Untar } 6 \text { hojas con grasa } \\
\text { de vaca y colocar el } \\
\text { cataplasma en la zona } \\
\text { afectada. }\end{array}$ \\
\hline & & $\begin{array}{l}\text { dolor } \\
\text { abdominal }\end{array}$ & $\begin{array}{l}\text { Infusión de } 3 \text { hojas o en } \\
\text { cocimiento de } 7 \text { hojas. }\end{array}$ \\
\hline chocho & $\begin{array}{l}\text { Lupinus mutabilis } \\
\text { Sweet. }\end{array}$ & sarna & $\begin{array}{l}\text { Con el agua de } 2 \text { kilos } \\
\text { del fruto chocho hervido } \\
\text { bañar al paciente. }\end{array}$ \\
\hline duraznillo & $\begin{array}{l}\text { Alonsoa } \\
\text { meridionalis }\end{array}$ & fiebre & $\begin{array}{l}\text { Hacer una infusión de } \\
150 \text { gr de hojas en } 10 \\
\text { litros de agua, bañar al } \\
\text { paciente. }\end{array}$ \\
\hline \multirow{3}{*}{ eucalipto } & \multirow{3}{*}{$\begin{array}{l}\text { Eucalyptus } \\
\text { globulus }\end{array}$} & bronquitis & $\begin{array}{l}\text { Infusión de una copa de } \\
\text { hojas, agregar una } \\
\text { cucharada de miel. }\end{array}$ \\
\hline & & resfrió, tos & Cocimiento de 3 hojas. \\
\hline & & reumatismo & $\begin{array}{l}\text { Cataplasma de un } \\
\text { puñado de hojas. }\end{array}$ \\
\hline flor de lope & & $\begin{array}{l}\text { infecciones } \\
\text { urinarias }\end{array}$ & Infusión de 10 flores. \\
\hline
\end{tabular}

\begin{tabular}{|c|c|c|c|}
\hline \multirow{2}{*}{ flor blanca } & & \multirow{2}{*}{$\begin{array}{l}\text { problemas } \\
\text { uterinos } \\
\text { leucorrea, } \\
\text { cáncer } \\
\end{array}$} & \multirow{2}{*}{$\begin{array}{l}\text { Infusión de } 20 \text { gr de flores. } \\
\text { Infusión de una cucharadita, } \\
\text { tomar con miel de abeja. }\end{array}$} \\
\hline & & & \\
\hline $\begin{array}{l}\text { flor de } \\
\text { muerto o } \\
\text { ayarosa }\end{array}$ & $\begin{array}{l}\text { Tagetes } \\
\text { patula }\end{array}$ & $\begin{array}{l}\text { neuralgia, } \\
\text { rinorrea } \\
\text { crónica }\end{array}$ & $\begin{array}{l}\text { Cocer una rama con otras } \\
\text { flores, bañar al paciente de } \\
\text { la frente hacia atrás, } \\
\text { peinándole el cabello. }\end{array}$ \\
\hline \multirow{2}{*}{ flor de novia } & & dismenorrea & $\begin{array}{l}\text { Infusión de } 50 \mathrm{gr} \text { de flores, } \\
\text { tomar } 3 \text { días antes y } \\
\text { durante la menstruación. }\end{array}$ \\
\hline & & alcoholismo & $\begin{array}{l}\text { Machacar } 10 \mathrm{gr} \text { de hojas y } \\
\text { tallos, agregar agua tibia, } \\
\text { colar y tomar una copita. }\end{array}$ \\
\hline flor de arena & \begin{tabular}{|l|l|} 
Tiquilia & \\
dichotoma \\
(R. \& P.) \\
Pers. \\
\end{tabular} & $\begin{array}{l}\text { leucorrea, } \\
\text { cáncer }\end{array}$ & $\begin{array}{l}\text { Infusión de una cucharadita, } \\
\text { tomar con miel de abeja. }\end{array}$ \\
\hline $\begin{array}{l}\text { Geranio } \\
\text { blanco }\end{array}$ & $\begin{array}{l}\text { Pelargonium } \\
\text { graveolens }\end{array}$ & ginecorragia & $\begin{array}{l}\text { Cocer un racimo de flores } \\
\text { con otras flores, tomar el } \\
\text { líquido; colocar las flores en } \\
\text { una gasa y envolver en la } \\
\text { zona inguinal. }\end{array}$ \\
\hline grama & \begin{tabular}{|l|} 
Cynodon \\
dactylon (L.) \\
Pers. \\
\end{tabular} & hipotensos & $\begin{array}{l}\text { Cocimiento de un puñado } \\
\text { de raíce. }\end{array}$ \\
\hline \multirow{3}{*}{ granadilla } & \multirow{3}{*}{$\begin{array}{l}\text { Passiflora } \\
\text { ligularis Juss. }\end{array}$} & $\begin{array}{l}\text { colesterolemi } \\
\text { a }\end{array}$ & Infusión de 1 a 2 hojas. \\
\hline & & hepatitis & $\begin{array}{l}\text { Infusión de } 4 \text { a } 5 \text { hojas, } \\
\text { tomar } 2 \text { veces al día. }\end{array}$ \\
\hline & & heridas & $\begin{array}{l}\text { Lavar con la infusión de las } \\
\text { hojas, las heridas. }\end{array}$ \\
\hline guayaba & \begin{tabular}{|l|}
$\begin{array}{l}\text { Psidium } \\
\text { guajava }\end{array}$ \\
\end{tabular} & resfrío & Cocimiento de las hojas. \\
\hline guanábana & $\begin{array}{l}\text { Annona } \\
\text { muricata L. }\end{array}$ & $\begin{array}{l}\text { sobrepeso, } \\
\text { obesidad, } \\
\text { gastritis, } \\
\text { dispepsia, } \\
\text { diabetes, } \\
\text { inflamación, } \\
\text { cáncer }\end{array}$ & $\begin{array}{l}\text { Infusión de } 5 \text { hojas o ingerir } \\
\text { el jugo } 3 \text { frutos. }\end{array}$ \\
\hline $\begin{array}{c}\text { helecho } \\
\text { macho }\end{array}$ & $\begin{array}{l}\text { Asplenium } \\
\text { serratum L. }\end{array}$ & $\begin{array}{l}\text { recaída, } \\
\text { dolor }\end{array}$ & $\begin{array}{l}\text { Cocimiento de una rama, } \\
\text { tomar en ayunas. }\end{array}$ \\
\hline \multirow[t]{2}{*}{ higuerilla } & \multirow[t]{2}{*}{$\begin{array}{l}\text { Ricinus } \\
\text { communis } L \text {. }\end{array}$} & $\begin{array}{l}\text { dolor } \\
\text { suprapúbico }\end{array}$ & $\begin{array}{l}\text { Moler } 10 \text { gr de } \\
\text { agregar maíz blanco, } \\
\text { aguardiente, colocar como } \\
\text { emplastos en la zona } \\
\text { afectada. }\end{array}$ \\
\hline & & fiebre & $\begin{array}{l}\text { Untar con aceite } 4 \text { hojas de } \\
\text { higuerilla y colocar en el } \\
\text { cuerpo (emplasto). }\end{array}$ \\
\hline hierba luisa & \begin{tabular}{|l|} 
Aloysia \\
triphylla \\
\end{tabular} & resfrío, tos & Infusión de 1 a 2 hojas. \\
\hline hierba mora & $\begin{array}{l}\text { Solanum } \\
\text { americanum } \\
\text { Mill. } \\
\end{array}$ & conjuntivitis & $\begin{array}{l}\text { Introducir } 1-2 \text { gotas del fruto } \\
\text { en la vista. }\end{array}$ \\
\hline \multirow{3}{*}{ hierba santa } & \multirow{3}{*}{$\begin{array}{l}\text { Cestrum } \\
\text { auriculatum }\end{array}$} & Disentería & $\begin{array}{l}\text { Chancar } 1 \text { a } 2 \text { tallos y } \\
\text { cocer, dar una cucharada al } \\
\text { niño y } 2 \text { al adulto. }\end{array}$ \\
\hline & & $\begin{array}{l}\text { Irregularidad } \\
\text { menstrual }\end{array}$ & $\begin{array}{l}\text { Infusión de } 60 \mathrm{gr} \text { de hojas, } \\
\text { tomar } 3 \text { veces al día. }\end{array}$ \\
\hline & & fiebre & $\begin{array}{l}\text { Machacar } 150 \text { gr de hojas y } \\
\text { mezclar con llonque y frotar } \\
\text { el cuerpo. }\end{array}$ \\
\hline \multirow{2}{*}{ hinojo } & \multirow{2}{*}{$\begin{array}{l}\text { Foeniculum } \\
\text { vulgare Mill. }\end{array}$} & cólicos & Infusión de 3 ramas. \\
\hline & & gripe & Infusión. \\
\hline horandilla & & fiebre & $\begin{array}{l}\text { Cocer } 1 \text { rama y bañar al } \\
\text { paciente, preparar en caldo } \\
\text { con huevo. }\end{array}$ \\
\hline $\begin{array}{l}\text { huarme } \\
\text { huarme }\end{array}$ & $\begin{array}{l}\text { Ageratum } \\
\text { conyzoides }\end{array}$ & prostatitis & $\begin{array}{l}\text { Cocimiento de 20gr de } \\
\text { hojas. }\end{array}$ \\
\hline \multirow{5}{*}{ lancetilla } & \multirow{5}{*}{$\begin{array}{l}\text { Alternanthera } \\
\text { philoxeroides } \\
\text { (C. Mart.) } \\
\text { Griseb. }\end{array}$} & $\begin{array}{l}\text { infección } \\
\text { urinaria y del } \\
\text { riñón }\end{array}$ & Infusión de una rama. \\
\hline & & $\begin{array}{l}\text { Fiebre, tos, } \\
\text { bronquitis }\end{array}$ & $\begin{array}{l}\text { Con el cocimiento } 2 \text { a } 3 \\
\text { manojos de hojas, bañar al } \\
\text { paciente (tibio). }\end{array}$ \\
\hline & & infección & $\begin{array}{l}\text { Con el cocimiento de } 2 \\
\text { manojos de hojas lavar la } \\
\text { zona afectada. }\end{array}$ \\
\hline & & $\begin{array}{l}\text { retención } \\
\text { urinaria, } \\
\text { inflamación } \\
\text { intestinal, } \\
\text { diarrea } \\
\end{array}$ & $\begin{array}{l}\text { Infusión de las } 5 \text { ramas y } \\
\text { flores e un litro de agua. }\end{array}$ \\
\hline & & $\begin{array}{l}\text { problemas } \\
\text { circulatorios }\end{array}$ & $\begin{array}{l}\text { Baños con infusión de } 100 \\
\text { gr de hojas en } 10 \text { litros de } \\
\text { aqua. }\end{array}$ \\
\hline
\end{tabular}




\begin{tabular}{|c|c|c|c|}
\hline \multirow{3}{*}{$\begin{array}{l}\text { lapas de } \\
\text { poro } \\
\text { lázaro } \\
\text { blanco }\end{array}$} & & $\begin{array}{l}\text { dolor } \\
\text { abdominal }\end{array}$ & $\begin{array}{l}\text { Calentar un manojo de } \\
\text { hojas envueltas en un } \\
\text { mantel, colocar el } \\
\begin{array}{lll}\text { cataplasma en el } \\
\text { abdomen. }\end{array}\end{array}$ \\
\hline & & dismenorrea & $\begin{array}{l}\text { Exprimir el zumo de las } \\
\text { hojas. }\end{array}$ \\
\hline & & $\begin{array}{l}\text { leucorrea, } \\
\text { cáncer }\end{array}$ & Infusión de hojas. \\
\hline linaza & $\begin{array}{l}\text { Linum } \\
\text { usitatissimun }\end{array}$ & inflamación & $\begin{array}{l}\text { Macerar } 30 \text { gr de raíz } \\
\text { con vino por } 8 \text { días, } \\
\text { tomar } 1 \text { copita diaria. }\end{array}$ \\
\hline lima dulce & \begin{tabular}{|l|} 
Citrus \\
aurantifolia \\
(Christmann) \\
Swingle \\
\end{tabular} & dismenorrea & $\begin{array}{l}\text { Infusión de } 50 \mathrm{gr} \text { de } \\
\text { tallo. }\end{array}$ \\
\hline \multirow[t]{3}{*}{ llantén } & \multirow[t]{3}{*}{$\begin{array}{l}\text { Plantago } \\
\text { major L. }\end{array}$} & $\begin{array}{l}\text { Inflamación, } \\
\text { infección }\end{array}$ & $\begin{array}{l}\text { Con el cocimiento de } \\
\text { las hojas de una } 1 \\
\text { planta lavar la zona } \\
\text { afectada, heridas, para } \\
\text { tomar se colocan las } \\
\text { hojas en agua hervida } \\
\text { fría. } \\
\text { Colocar } 3 \text { a } 5 \text { hojas de } \\
\text { una infusión como } \\
\text { cataplasma. }\end{array}$ \\
\hline & & insomnio & Tomar en infusión. \\
\hline & & heridas & $\begin{array}{l}\text { Lavar con infusión de } 2 \\
\text { a } 4 \text { hojas las heridas. }\end{array}$ \\
\hline llive & & hemorragias & $\begin{array}{l}\text { Al sacar la corteza se } \\
\text { obtiene una goma, ésta } \\
\text { se coloca en la herida } \\
\text { (cataplasma). }\end{array}$ \\
\hline maíz & Zea mays & $\begin{array}{l}\text { inflamación } \\
\text { del ovario }\end{array}$ & $\begin{array}{l}\text { Tomar en infusión } 50 \mathrm{gr} \\
\text { del pelo, como agua de } \\
\text { tiempo. }\end{array}$ \\
\hline $\begin{array}{c}\text { maíz } \\
\text { blanco }\end{array}$ & & antimonia & $\begin{array}{l}1 \mathrm{gr} \text { de semillas usar en } \\
\text { baño. }\end{array}$ \\
\hline $\begin{array}{c}\text { mala } \\
\text { hierba }\end{array}$ & \begin{tabular}{|l|} 
Rumex \\
conglomeratu \\
s
\end{tabular} & $\begin{array}{l}\text { infección del } \\
\text { estómago }\end{array}$ & $\begin{array}{l}\text { Machacar la raíz, } \\
\text { colocar en agua } \\
\text { hervida, (infusión) tomar } \\
\text { en ayunas. }\end{array}$ \\
\hline malbata & & dolor de riñón & Cocimiento de 5 hojas. \\
\hline \multirow{7}{*}{ malva } & \multirow{7}{*}{$\begin{array}{c}\text { Malva } \\
\text { silvestris }\end{array}$} & $\begin{array}{l}\text { irritación del } \\
\text { ojo, catarata }\end{array}$ & $\begin{array}{l}\text { Colocar } 3 \text { gotas de } \\
\text { infusión de } 20 \text { gr de } \\
\text { flores en cada ojo y } \\
\text { cerrad los ojos por } 5 \\
\text { segundos, usar por } 15 \\
\text { días. }\end{array}$ \\
\hline & & $\begin{array}{l}\text { dolor } \\
\text { suprapúbico, } \\
\text { retención de } \\
\text { orina }\end{array}$ & $\begin{array}{l}\text { Con el cocimiento de } \\
\text { las hojas de } 2 \text { a } 3 \\
\text { manojos de hojas hacer } \\
\text { baño de asiento. }\end{array}$ \\
\hline & & & $\begin{array}{l}\text { Exprimir el zumo de } 2 \text { a } \\
3 \text { plantas, tomar } 1 \text { vaso } \\
\text { diario. }\end{array}$ \\
\hline & & fiebre & $\begin{array}{l}\text { Machacar } 3 \text { a } 4 \text { hojas, } \\
\text { sacar el zumo y mezclar } \\
\text { con agua de linaza, } \\
\text { tomar } 1 \text { taza. }\end{array}$ \\
\hline & & estreñimiento & Cocimiento de 30 flores. \\
\hline & & tos & $\begin{array}{l}\text { Cocimiento de la flor, } \\
\text { tomar en la mañana por } \\
4 \text { a } 5 \text { días. }\end{array}$ \\
\hline & & heridas & $\begin{array}{l}\text { Lavar la herida con } \\
\text { infusión de las hojas. }\end{array}$ \\
\hline \multirow{5}{*}{$\begin{array}{l}\text { manzanill } \\
\text { a }\end{array}$} & \multirow{5}{*}{$\begin{array}{l}\text { Matricaria } \\
\text { recutita } L \text {. }\end{array}$} & buen parto & $\begin{array}{l}\text { Infusión de una manojo } \\
\text { de la planta. }\end{array}$ \\
\hline & & Cólicos & $\begin{array}{l}\text { Infusión de } 2 \text { ramas. } \\
\text { Cocimiento de un } \\
\text { manojo de tallos, hojas } \\
\text { y flores. }\end{array}$ \\
\hline & & frio & $\begin{array}{l}\text { Infusión de un manojo } \\
\text { de tallos, hojas y flores }\end{array}$ \\
\hline & & $\begin{array}{l}\text { infección de } \\
\text { los genitales, } \\
\text { dolor, edema }\end{array}$ & Infusión de una rama. \\
\hline & & insomnio & Infusión de un manojo \\
\hline
\end{tabular}

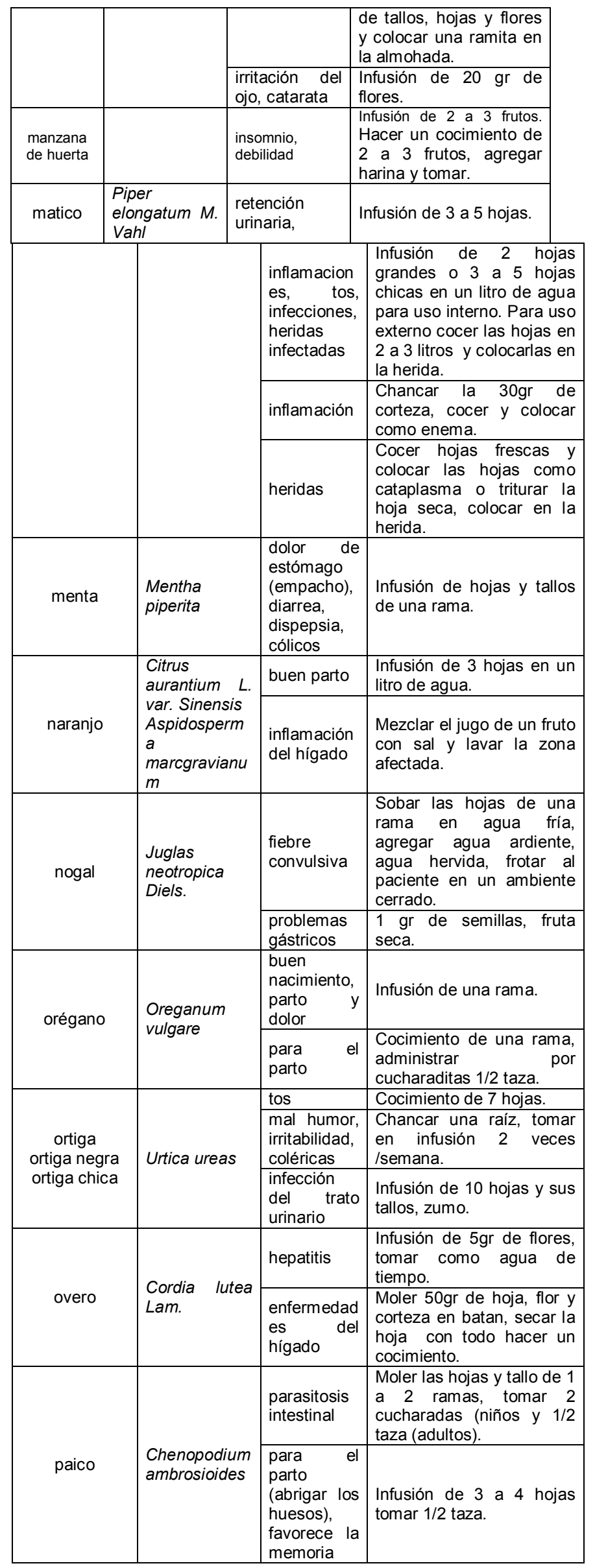




\begin{tabular}{|c|c|c|c|}
\hline & & $\begin{array}{l}\text { hepatitis, } \\
\text { irritabilidad, } \\
\text { mal humor }\end{array}$ & $\begin{array}{l}\text { Cocimiento de } 2 \text { hojas, } \\
\text { tomar } 1 \text { a } 2 \text { tazas por día. }\end{array}$ \\
\hline $\begin{array}{l}\text { pajunga o } \\
\text { cabillo }\end{array}$ & & $\begin{array}{l}\text { inflamación } \\
\text { del riñón, } \\
\text { cálculos }\end{array}$ & Cocimiento de la raíz. \\
\hline palto & $\begin{array}{l}\text { Persea } \\
\text { americana } \\
\text { Mill. var. } \\
\text { americana }\end{array}$ & $\begin{array}{l}\text { infamación } \\
\text { de riñones, } \\
\text { infecciones, } \\
\text { leucorrea }\end{array}$ & $\begin{array}{l}\text { Hervir } 1 \text { semilla en un litro } \\
\text { y medio de agua, agregar } \\
3 \text { gotas de sangre de } \\
\text { grado y hacer lavados. }\end{array}$ \\
\hline pan de árbol & $\begin{array}{l}\text { Artcarpus } \\
\text { altilis }\end{array}$ & $\begin{array}{l}\text { inflamación, } \\
\text { hernia }\end{array}$ & $\begin{array}{l}\text { Infusión de } \\
\text { resina. }\end{array}$ \\
\hline papa & $\begin{array}{l}\text { Solanum } \\
\text { tuberosum L. }\end{array}$ & luxaciones & $\begin{array}{l}\text { Cocer las hojas frescas } \\
\text { de la planta completa, } \\
\text { tomar una copa } 3 \\
\text { veces/dia. los tallos y } \\
\text { hojas se usan para } \\
\text { preparar una crema. }\end{array}$ \\
\hline papaya & $\begin{array}{l}\text { Carica } \\
\text { papaya } L .\end{array}$ & hepatitis & $\begin{array}{l}\text { Moler } 7 \text { semillas frescas, } \\
\text { tomar el extracto por } 7 \\
\text { días. }\end{array}$ \\
\hline \multirow[b]{2}{*}{ pashquete } & \multirow[b]{2}{*}{ Celosia sp. } & buen parto & $\begin{array}{l}\text { Infusión de } 30 \text { hojas para } \\
\text { dar un baño. }\end{array}$ \\
\hline & & $\begin{array}{l}\text { infección } \\
\text { del trato } \\
\text { urinario }\end{array}$ & Infusión de 10 hojas. \\
\hline pepinillo & $\begin{array}{l}\text { Cucumis } \\
\text { sativus } L \text {. }\end{array}$ & hepatitis & $\begin{array}{l}\text { Rallar un fruto y tomar el } \\
\text { zumo con miel de abeja y } \\
\text { sangre de grado. }\end{array}$ \\
\hline \multirow{4}{*}{ perejil } & \multirow{4}{*}{$\begin{array}{l}\text { Petroselinum } \\
\text { crispum (Mill.) } \\
\text { Fuss }\end{array}$} & $\begin{array}{l}\text { ayuda a la } \\
\text { expulsión del } \\
\text { feto (buen } \\
\text { nacimiento) }\end{array}$ & $\begin{array}{l}\text { Infusión de } 10 \text { hojas y sus } \\
\text { tallos. }\end{array}$ \\
\hline & & $\begin{array}{l}\text { fiebre } \\
\text { intestinal, } \\
\text { náuseas, } \\
\text { diarrea, } \\
\text { vómitos }\end{array}$ & $\begin{array}{l}\text { Machacar } 5 \text { raíces, colocar } \\
\text { en agua hervida, agregar } \\
\text { flor de manzana ácida y } \\
\text { limón, tomar como agua de } \\
\text { tiempo. }\end{array}$ \\
\hline & & $\begin{array}{l}\text { dismenorrea, } \\
\text { problemas } \\
\text { renales, } \\
\text { cardiacos. }\end{array}$ & $\begin{array}{l}\text { Infusión de un manojo de } \\
\text { hojas. }\end{array}$ \\
\hline & & $\begin{array}{l}\text { infección del } \\
\text { trato urinario }\end{array}$ & $\begin{array}{l}\text { Machacar el tallo, tomar el } \\
\text { zumo. }\end{array}$ \\
\hline $\begin{array}{l}\text { planta } \\
\text { coronada }\end{array}$ & & $\begin{array}{l}\text { ayuda a la } \\
\text { expulsión del } \\
\text { feto }\end{array}$ & $\begin{array}{l}\text { Infusión de una flor, tomar } \\
1 / 2 \text { taza. }\end{array}$ \\
\hline $\begin{array}{l}\text { platanito del } \\
\text { naucasha }\end{array}$ & & $\begin{array}{l}\text { ayuda a la } \\
\text { expulsión del } \\
\text { feto, arregla } \\
\text { al niño }\end{array}$ & Infusión de 12 flores. \\
\hline piñón verde & $\begin{array}{l}\text { Jatropa } \\
\text { curcas } L .\end{array}$ & $\begin{array}{l}\text { diarrea, } \\
\text { herida }\end{array}$ & $\begin{array}{l}\text { Sacar la resina del tallo y } \\
\text { colocarla en medio vaso de } \\
\text { agua fría, tomar } 2 \text { a } 3 \\
\text { veces en la mañana por } 2 \text { a } \\
3 \text { días; para las heridas se } \\
\text { agrega resina de algodón. }\end{array}$ \\
\hline \multirow{2}{*}{$\begin{array}{l}\text { pie de perro o } \\
\text { manayupa }\end{array}$} & \multirow{2}{*}{$\begin{array}{l}\text { Desmodium } \\
\text { Molliculum }\end{array}$} & $\begin{array}{l}\text { inflamación, } \\
\text { cálculos } \\
\text { renales }\end{array}$ & $\begin{array}{l}\text { Infusión de } 10 \text { ramitas } \\
\text { medianas en un litro de } \\
\text { agua. }\end{array}$ \\
\hline & & $\begin{array}{l}\text { buen parto } \\
\text { inflamación } \\
\text { del ovario }\end{array}$ & $\begin{array}{l}\text { Infusión de } 20 \mathrm{gr} \text { de hojas } \\
\text { en un litro de agua. }\end{array}$ \\
\hline \multirow{3}{*}{ poleo } & \multirow{3}{*}{$\begin{array}{l}\text { Mentha } \\
\text { pulegium }\end{array}$} & $\begin{array}{l}\text { leucorrea, } \\
\text { cáncer }\end{array}$ & $\begin{array}{l}\text { Cocimiento de } 8 \text { ramas en } \\
\text { un litro de agua. }\end{array}$ \\
\hline & & diarrea & Cocimiento de 10 hojas. \\
\hline & & $\begin{array}{l}\text { cólicos, } \\
\text { reumatismo }\end{array}$ & $\begin{array}{l}\text { Infusión de las hojas, frotar } \\
\text { por todo el cuerpo. }\end{array}$ \\
\hline puru puru & $\begin{array}{l}\text { Calceolaria } \\
\text { cuneiformis }\end{array}$ & calambres & Infusión de semillas. \\
\hline pushqueta & & gripe & $\begin{array}{l}\text { Infusión de } 15 \text { gr de hojas } \\
\text { en un litro de agua.. }\end{array}$ \\
\hline quintutui & & $\begin{array}{l}\begin{array}{l}\text { pulsario } \\
\text { (caída del } \\
\text { vientre) }\end{array} \\
\end{array}$ & $\begin{array}{l}\text { Frotar } 6 \text { hojas con el agua } \\
\text { de los } 7 \text { espíritus, colocar } \\
\text { en el ombligo. }\end{array}$ \\
\hline retama & $\begin{array}{l}\text { Spartium } \\
\text { junceum L. }\end{array}$ & hepatitis & $\begin{array}{l}\text { Con el cocimiento de una } \\
\text { planta entera bañar al } \\
\text { paciente. }\end{array}$ \\
\hline rosa & $\begin{array}{l}\text { Rosa canina } \\
\text { L. }\end{array}$ & $\begin{array}{l}\text { problemas } \\
\text { cardiacos, } \\
\text { circulatorios, }\end{array}$ & Infusión de una flor. \\
\hline
\end{tabular}

\begin{tabular}{|c|c|c|c|}
\hline & & $\begin{array}{l}\text { hipertensión } \\
\text { arterial }\end{array}$ & \\
\hline & & pena & $\begin{array}{l}\text { Tomar infusión de una flor } \\
\text { mas agua bendita. }\end{array}$ \\
\hline & & recaída & Infusión de 6 flores. \\
\hline \multirow{2}{*}{ rosa blanca } & & $\begin{array}{l}\text { depresión, } \\
\text { autoestima } \\
\text { baja }\end{array}$ & Infusión de 5 flores, zumo. \\
\hline & & $\begin{array}{l}\text { conjuntivitis } \\
\text { crónica }\end{array}$ & $\begin{array}{l}\text { Remojar una flor con agua } \\
\text { hervida fría, almacenar en } \\
\text { un gotero como colirio. }\end{array}$ \\
\hline \multirow{5}{*}{ ruda } & \multirow{5}{*}{$\begin{array}{l}\text { Ruta } \\
\text { graveolens } L .\end{array}$} & $\begin{array}{l}\text { infección del } \\
\text { trato urinario }\end{array}$ & Infusión de 3 ramas, zumo. \\
\hline & & mareos & $\begin{array}{l}\text { Sobar con un manojo de } \\
\text { hojas, la frente y toda la } \\
\text { cabeza, hacer oler. }\end{array}$ \\
\hline & & $\begin{array}{l}\text { irritación del } \\
\text { ojo, catarata }\end{array}$ & $\begin{array}{l}\text { Calentar un puñado de } \\
\text { flores y colocarlas en los } \\
\text { ojos. }\end{array}$ \\
\hline & & dolor de oído & $\begin{array}{l}\text { Sobar un puñado de flores } \\
\text { y colocarlas en el oído. }\end{array}$ \\
\hline & & $\begin{array}{l}\text { nauseas, } \\
\text { envidia }\end{array}$ & $\begin{array}{l}\text { Infusión de las hojas, frotar } \\
\text { por todo el cuerpo }\end{array}$ \\
\hline \multirow{3}{*}{ sábila } & \multirow{3}{*}{$\begin{array}{l}\text { Aloe vera (L.) } \\
\text { Burm. f. }\end{array}$} & $\begin{array}{l}\text { infección de } \\
\text { heridas }\end{array}$ & $\begin{array}{l}\text { Cortar } 3 \text { a } 4 \text { hojas y colocar } \\
\text { en agua para que salga la } \\
\text { resina, agregar harina de } \\
\text { maíz blanco, vinagre, } \\
\text { colocar como emplastos } \\
\text { en la zona afectada. }\end{array}$ \\
\hline & & $\begin{array}{l}\text { úlceras del } \\
\text { estómago, } \\
\text { diarrea } \\
\text { crónica }\end{array}$ & Infusión de 3 hojas. \\
\hline & & inflamación & $\begin{array}{l}\text { Comer en trozos pequeños } \\
\text { la pulpa de una hoja sin la } \\
\text { corteza. }\end{array}$ \\
\hline santanuaga & & $\begin{array}{l}\text { buen parto, } \\
\text { contracciòn } \\
\text { uterina }\end{array}$ & $\begin{array}{l}\text { Infusión de } 15 \text { flores o de } \\
40 \text { hojas }\end{array}$ \\
\hline
\end{tabular}

\begin{tabular}{|c|c|c|c|}
\hline $\begin{array}{l}\text { sangre de } \\
\text { grado }\end{array}$ & $\begin{array}{l}\text { Croton } \\
\text { lechleri }\end{array}$ & leucorrea & $\begin{array}{l}\text { Lavados vaginales, colocar } \\
3 \text { gotas de resina en un } \\
\text { vaso con agua y tomar a la } \\
\text { hora de dormir por } 9 \text { a } 12 \\
\text { días. }\end{array}$ \\
\hline $\begin{array}{l}\text { santan } \\
\text { vargas }\end{array}$ & $\begin{array}{l}\text { Oreocalis } \\
\text { glandiflora }\end{array}$ & leucorrea & $\begin{array}{l}\text { Cocimiento de un manojo } \\
\text { de hojas. }\end{array}$ \\
\hline \multirow{5}{*}{ sauco } & \multirow{5}{*}{$\begin{array}{l}\text { Sambucus } \\
\text { peruviana } \\
\text { H.B.K. }\end{array}$} & buen parto & Infusión de las hojas. \\
\hline & & diarrea & $\begin{array}{l}\text { Infusión de } 10 \text { frutos con } \\
\text { un poquito de agua } \\
\text { ardiente. }\end{array}$ \\
\hline & & fiebre & $\begin{array}{l}\text { Macerar } 3 \text { hojas con agua } \\
\text { ardiente y colocar en la } \\
\text { frente (emplasto). }\end{array}$ \\
\hline & & $\begin{array}{l}\text { dolor de } \\
\text { cabeza, } \\
\text { (chirapa) }\end{array}$ & $\begin{array}{l}\text { Machacar } 10 \text { a } 20 \text { frutos, } \\
\text { tomar el jugo. Mezclar } 5 \\
\text { hojas con orina y agua } \\
\text { ardiente, colocar el } \\
\text { emplasto en la cabeza. }\end{array}$ \\
\hline & & salpullido & $\begin{array}{l}\text { Baños con infusión de } \\
\text { hojas. }\end{array}$ \\
\hline \multirow{3}{*}{ subsacha } & \multirow{3}{*}{$\begin{array}{l}\text { Stachys } \\
\text { arvensis }\end{array}$} & dispepsia & $\begin{array}{l}\text { Infusión de un manojo de } \\
\text { hojas }\end{array}$ \\
\hline & & cólico & Infusión de una rama. \\
\hline & & diarrea & Infusión de 10 hojas. \\
\hline $\begin{array}{l}\text { suelda con } \\
\text { suelda }\end{array}$ & $\begin{array}{l}\text { Phoradendro } \\
n \text { punctatum }\end{array}$ & $\begin{array}{l}\text { fracturas, } \\
\text { esguinces, } \\
\text { luxaciones }\end{array}$ & $\begin{array}{l}\text { Cataplasma de un manojo } \\
\text { de hojas. Frotar con } 5 \\
\text { ramas, la zona afectada. } \\
\text { Mezclar un manojo de } \\
\text { hojas con manteca de } \\
\text { chancho y vendar la zona } \\
\text { afectada (emplasto). }\end{array}$ \\
\hline talla & $\begin{array}{l}\text { Caesalpinia } \\
\text { spinosa } \\
\text { (Mol.) Ktze. }\end{array}$ & amigdalitis & $\begin{array}{l}\text { Cocer } 6 \text { frutos hasta que } \\
\text { su consistencia sea como } \\
\text { una crema, colocar como } \\
\text { cataplasma en } \\
\text { amígdalas. }\end{array}$ \\
\hline toronjil & $\begin{array}{l}\text { Melissa } \\
\text { officinalis L. }\end{array}$ & $\begin{array}{l}\text { problemas } \\
\text { de memoria }\end{array}$ & $\begin{array}{l}\text { Infusión de } 10 \text { hojas, tomar } \\
30 \text { días antes de la fecha } \\
\text { probable de parto. }\end{array}$ \\
\hline
\end{tabular}


ECIPERÚ

\begin{tabular}{|c|c|c|c|}
\hline & & $\begin{array}{l}\text { para } \\
\text { calentar el } \\
\text { cuerpo para } \\
\text { el parto, el } \\
\text { buen } \\
\text { nacimiento }\end{array}$ & Infusión de una rama. \\
\hline & & $\begin{array}{l}\text { enfermedad } \\
\text { gástrica }\end{array}$ & $\begin{array}{l}\text { Infusión de las hojas de } \\
\text { una rama. }\end{array}$ \\
\hline \multirow[b]{2}{*}{ tomatillo } & \multirow[b]{2}{*}{$\begin{array}{l}\text { Physalis } \\
\text { pubescens }\end{array}$} & gripe & Infusión de 5 hojas. \\
\hline & & fiebre & $\begin{array}{l}\text { sobar con } 50 \text { hojas en agua } \\
\text { tibia y bañar todo el cuerpo }\end{array}$ \\
\hline tunjuli & & luxaciones & $\begin{array}{l}\text { moler la raíz y la corteza, } \\
\text { calentar y colocar en la } \\
\text { zona afectada (cataplasma) }\end{array}$ \\
\hline \multirow[t]{2}{*}{ valeriana } & \multirow{2}{*}{$\begin{array}{l}\text { Valeriana } \\
\text { officinalis }\end{array}$} & insomnio & $\begin{array}{l}\text { Cocimiento de } 10 \text { a } 15 \mathrm{gr} \\
\text { de raíz. }\end{array}$ \\
\hline & & debilidad & $\begin{array}{l}\text { Cocimiento de una planta } \\
\text { entera. }\end{array}$ \\
\hline \multirow{3}{*}{ verbena } & \multirow{3}{*}{$\begin{array}{l}\text { Verbena } \\
\text { litorales }\end{array}$} & inflamación & $\begin{array}{l}\text { Chancar los tallos y hojas } \\
\text { de una planta, mezclarla } \\
\text { con huevo batido a punto } \\
\text { de nieve, colocar en } \\
\text { abdomen y espalda } \\
\text { (emplasto). }\end{array}$ \\
\hline & & $\begin{array}{l}\text { inflamación } \\
\text { del hígado, } \\
\text { cólera }\end{array}$ & $\begin{array}{l}\text { Cocimiento los tallos y } \\
\text { hojas de una planta, tomar } \\
1 \text { a } 2 \text { tazas por día. }\end{array}$ \\
\hline & & $\begin{array}{lr}\begin{array}{l}\text { tos, } \\
\text { dolor riebre, } \\
\text { huesos }\end{array} \\
\end{array}$ & $\begin{array}{l}\text { Infusión de una rama, } \\
\text { agregar limón y miel de } \\
\text { abeja. }\end{array}$ \\
\hline violeta & Viola odorata & gripe & Infusión de 15 gr de hojas. \\
\hline vira vira & $\begin{array}{l}\text { Senecio } \\
\text { canescens }\end{array}$ & tos & $\begin{array}{l}\text { Gárgaras con la infusión de } \\
4 \text { a } 5 \text { hojas. }\end{array}$ \\
\hline yacón & $\begin{array}{l}\text { Smallanthus } \\
\text { sonchifolius }\end{array}$ & fiebre & $\begin{array}{l}\text { Cortar en rodajas el } \\
\text { tubérculo y colocar en la } \\
\text { frente (cataplasma). }\end{array}$ \\
\hline zarza & Rubus roseus & debilidad & $\begin{array}{l}\text { Untar } 2 \text { hojas de zarza con } \\
\text { grasa o sangre de ganado } \\
\text { y colocar en las sienes } \\
\text { (emplasto). }\end{array}$ \\
\hline
\end{tabular}

Por otro lado la recolección de 100 especies ha permitido que estas sean identificadas taxonómicamente por el equipo de trabajo y se cultiven en un jardín botánico en la Universidad Nacional Toribio Rodríguez de Mendoza, permitiendo la conservación de las especies y estudiarlas más ampliamente acerca de sus propiedades medicinales y potencial agroindustrial.

Los investigadores argumentan que para identificar a las especies de plantas medicinales existe la necesidad de contar con una relación confiable entre nombres vulgares y científicos, pues no todas las plantas se llegan a observar [4].

El cultivo regular de plantas medicinales y su transformación industrial es una alternativa para los países latinoamericanos que ayudaría a resolver problemas económicos, sociales y medioambientales.

\section{CONCLUSIONES}

1. Se recolecto información de 238 plantas medicinales usadas por los agentes comunitarios tradicionales del nororiente amazónico peruano, para tratar o prevenir enfermedades respiratorias, digestivas, genitourinarias, osteoarticular y emocional; 155 son usadas individualmente; 83 con otras plantas; 193 son usadas cotidianamente por los pobladores de las 21 comunidades visitadas, pertenecientes a las regiones Amazonas, Loreto y San Martín .

2. Fueron cultivadas e identificadas taxonómicamente 100 plantas medicinales en el jardín botánico de la Universidad Nacional Toribio Rodríguez de Mendoza de Amazonas.

3. Las plantas del nororiente amazónico peruano tienen un gran potencial agroindustrial: medicinal, culinario, plaguicida, etnoveterinaria, cosmético entre otros.

\section{REFERENCIAS}

[1] W. Gutiérrez, Ponencia: Recursos Naturales en la Amazonia. II Jornada Binacional de Químicos Farmacéuticos y Bioquímicos PerúEcuador. VIII Expo Farmacia Internacional. Iquitos, Perú. 2006

[2] CONAF, Gobierno de Chile, En Codpa se recupera la Medicina Tradicional, 2008. Disponible en hpp//www. Corporación Nacional Forestal - Chile.mht. Acceso el 02 de Marzo del 2009.

[3] S. Campos Jiménez, Esquivel Blanco, M. Chacón Montero, Proyecto de plantas medicinales colegio técnico profesional de Cóbano. Colegio Técnico Profesional de Cóbano, Instituto Nacional de biodiversidad de Costa Rica. 2006.

[4] A. Brack, Biodiversidad, pobreza y bionegocios, PNUD, Lima, Perú. 2004

[5] L. P. Kvist, I. Oré, A. Gonzales, C. Llapapasca, Estudio plantas medicinales en la amazonia peruana: una evaluación de ocho métodos etnobotánicos. Folia Amazónica 12 (1-2) (2001) 53-73.

[6] F. Kahn, Palmeras nativas y manejo de bosques pantanosos de la Amazonia Peruana. Biota, 95 (1989) 58-63.

E-mail: mprq2007@hotmail.com 